\title{
BMJ Open Disabling chronic conditions in childhood and socioeconomic disadvantage: a systematic review and meta-analyses of observational studies
}

\author{
Nicholas J Spencer, Clare M Blackburn, Janet M Read
}

To cite: Spencer NJ, Blackburn CM, Read JM. Disabling chronic conditions in childhood and socioeconomic disadvantage: a systematic review and meta-analyses of observational studies. BMJ Open 2015;5:e007062. doi:10.1136/bmjopen-2014007062

- Prepublication history and additional material is available. To view please visit the journal (http://dx.doi.org/ 10.1136/bmjopen-2014007062).

Received 30 October 2014 Revised 23 July 2015 Accepted 30 July 2015
CrossMark

Warwick Medical School, University of Warwick, Coventry, UK

\section{Correspondence to} Professor Nicholas J Spencer;

n.j.spencer@warwick.ac.uk

\section{ABSTRACT}

Objective: To determine the association of socioeconomic disadvantage with the prevalence of childhood disabling chronic conditions in high-income countries.

Study design: Systematic review and meta-analyses. Data sources: 6 electronic databases, relevant websites, reference lists and experts in the field.

Study selection: 160 observational studies conducted in high-income countries with data on socioeconomic status and disabling chronic conditions in childhood, published between 1 January 1991 and 31 December 2013.

Data extraction and synthesis: Abstracts were reviewed, full papers obtained, and papers identified for inclusion by 2 independent reviewers. Inclusion decisions were checked by a third reviewer. Where reported, ORs were extracted for low versus high socioeconomic status. For studies reporting raw data but not ORs, ORs were calculated. Narrative analysis was undertaken for studies without data suitable for meta-analysis.

Results: 126 studies had data suitable for metaanalysis. ORs for risk estimates were: all-cause disabling chronic conditions $1.72(95 \% \mathrm{Cl} 1.48$ to 2.01); psychological disorders $1.88(95 \% \mathrm{Cl} 1.68$ to 2.10); intellectual disability $2.41(95 \% \mathrm{Cl} 2.03$ to 2.86); activity-limiting asthma $2.20(95 \% \mathrm{Cl} 1.87$ to 2.85); cerebral palsy $1.42(95 \% \mathrm{Cl} 1.26$ to 1.61$)$; congenital abnormalities 1.41 (95\% Cl 1.24 to 1.61$)$; epilepsy 1.38 (95\% Cl 1.20 to 1.59); sensory impairment 1.70 (95\% Cl 1.39 to 2.07). Heterogeneity was high across most estimates $\left(\mathrm{I}^{2}>75 \%\right)$. Of the 34 studies without data suitable for meta-analysis, 26 reported results consistent with increased risk associated with low socioeconomic status.

Conclusions: The findings indicate that, in highincome countries, childhood disabling chronic conditions are associated with social disadvantage. Although evidence of an association is consistent across different countries, the review provides limited evidence to explain the association; future research, using longitudinal data, will be required to distinguish low socioeconomic status as the cause or consequence of childhood disabling chronic conditions and the aetiological pathways and mechanisms.

\section{Strengths and limitations of this study}

- The extensive literature reviewed used a rigorous methodology, and the consistent findings across different country settings suggest the conclusions are robust.

- The high degree of heterogeneity in the pooled estimates represents a threat to their validity; however, the majority of the estimates were robust to sensitivity analysis.

- This review, using both quantitative and qualitative data synthesis, is the first to draw together a large body of studies on the relationship of socioeconomic disadvantage with disabling chronic conditions in childhood in high income countries.

\section{INTRODUCTION}

Disabling chronic conditions in childhood are a major global public health issue in high-income as well as low-income countries. Estimates of these conditions in most highincome countries fall between $3.5 \%$ and $8.0 \%$ of children aged $0-18$ years, with some countries reporting that prevalence is increasing. ${ }^{1}$ Although children with these conditions can lead rich and fulfilling lives, many experience poor educational outcomes, ${ }^{2}$ social adversity, ${ }^{3}$ lower levels of social participation $^{4}$ and sometimes pain. ${ }^{4}$ Reducing the prevalence of these conditions in childhood, and the impact on children and their families is, therefore, desirable. Disability is increasingly seen as a dynamic interaction between health conditions and contextual factors, both personal and environmental', ', with social and genetic factors coming together in complex ways to increase a child's risk of developing a chronic disabling condition. ${ }^{5}$

The first World Report on Disability ${ }^{3}$ identifies poverty and socioeconomic disadvantage as possible cause and consequence of 
disability. This report, however, focuses on adults in developed countries and does not consider the evidence for this association in childhood. Low socioeconomic status (SES) is likely to be both a cause and consequence of disability in childhood, but if and where the low SES sits on the causal pathway remains unclear. Although many studies have examined the association between childhood disabling chronic conditions and SES, to date there has been no published systematic review of studies examining the association in high-income countries. As a result, there is no synthesised evidence on risk, or assessment of the quality of this research. The only available systematic review of literature on this association in low-income and middle-income countries indicated that the evidence was inconsistent and inconclusive, and that many studies had a high/medium risk of bias. ${ }^{6}$

To address this important evidence gap, we undertook a systematic review and meta-analyses of studies in highincome countries to examine the association of SES with childhood disabling chronic conditions. In this paper, the term disabling chronic conditions refers to the range of conditions and impairments lasting at least 6 months that limit a child's normal daily activity. We examine the role of SES in all-cause disabling chronic conditions and in a range of condition groups. As the first systematic review in this area, it provides rigorous evidence on the association between disabling chronic conditions in childhood and SES that will contribute to understanding how to reduce the prevalence and impact of these diverse and complex conditions in childhood.

The main focus of this paper is a quantitative synthesis of the data with meta-analyses of studies that report either ORs or raw data from which these can be estimated. A brief narrative analysis of those studies that could not be entered into meta-analysis is included.

\section{METHODS}

\section{Search strategy and selection criteria}

We searched MEDLINE, PsycINFO, ASSIA, EMBASE, Web of Science and EconLit for studies reported between 1 January 1991 and 31 December 2013. For each database, a search strategy using a combination of free text and controlled vocabulary terms was developed (see example in box 1). We used search terms for the exposure of interest (socioeconomic disadvantage) and the outcomes of interest (childhood disabling chronic conditions). Searches of relevant national and international government and non-government organisations' internet sites were conducted, and reference lists of included studies were screened.

We contacted international experts to identify studies not captured in other searches. English language publications only were included. A total of 5480 titles and abstracts, and 799 full-text articles and reports were independently screened by two reviewers (JMR and NJS). Of the full-text articles and reports, data were extracted onto standard forms for potentially relevant studies by one reviewer (NJS) and checked by a second reviewer $(\mathrm{CMB}$; weighted $\mathrm{k}=0.91)$. Differences of opinion were resolved in discussion with the third reviewer (JMR). Figure 1 shows the flow chart of study selection.

\section{Box 1 Sample search strategy: Ovid Medline}

1. $\operatorname{exp~Socioeconomic~Factors/(276257)~}$

2. social disadvantage.ab,ti. (370)

3. social deprivation.ab,ti. (722)

4. low income.ab,ti. (11585)

5. social exclusion.ab,ti. (410)

6. Ione parenthood.ab,ti. (24)

7. parental disability.ab,ti. (15)

8. 1 or 2 or 3 or 4 or 5 or 6 or 7 (281054)

9. childhood disabilit+ACo-.ab,ti. (201)

10. exp Disabled children/(3092)

11. chronic illness+ACo-ab,ti. (7432)

12. asthma.ab,ti. (86271)

13. cerebral palsy.ab,ti. (10905)

14. epilepsy.ab,ti. (52945)

15. hearing impairment.ab,ti. (4631)

16. visual impairment.ab,ti. (4265)

17. congenital abnormalit+ACo-.ab,ti. (4285)

18. ((long-term illness+ACo- or long-standing illness+ACo-) and limiting).ab,ti. (126)

19. activity limiting illness+ACo-.ab,ti. (1)

20. exp+ACl-Attention Deficit and Disruptive BehaviorDisorders $+\mathrm{ACl}-/(17055)$

21. emotional disorders.mp.orexp Child Behavior Disorders/epidemiology (1066)

22. +ACo-Mental Retardation/(28678)

23. +ACo-Learning Disorders/(7918)

24. +ACo-Communication Disorders/(875)

25. or/9-24 (224506)

26. 8 and $25(7275)$

27. (addiction+ACo- or addicted or drug taking or smoking).mp (172219)

28. exp Substance-Related Disorders/(310751)

29. alcohol+ACo-.ab,ti. (176708)

30. +ACo-Substance-Related Disorders/epidemiology or +ACoSmoking/epidemiology or +ACo-Opioid-Related Disorders/ epidemiology or +ACo-Alcoholism/ep (3642)

31. $\operatorname{exp~HIV/(67947)~}$

32. exp Acquired Immunodeficiency Syndrome/(68867)

33. or/27-32 (665725)

34. 26 not $33(6435)$

35. expcanada/or exp united states/or exp japan/or exp $+\mathrm{ACl}$-republic of korea+ACI-/or expaustralia/or expaustria/or expbelgium/or expczech republic/or exphungary/or exppoland/or expslovakia/or expslovenia/or expfinland/or france/or expgermany/or exp great britain/or expgreece/or expiceland/ or exp ireland/or expitaly/or expluxembourg/or expnetherlands/or expportugal/or expdenmark/or expnorway/or expsweden/or expspain/or expswitzerland/or exp new zealand/or exp Israel/(1985719)

36. 34 and 35 (2806)

37. limit 36 to (english language and humans) (2583)

38. limit 37 to $y r+A D 0 A l g-1985$-Current+ACI- (2318)

39. limit 38 to $+\mathrm{ACl}$-all child (0 to 18 years) $+\mathrm{ACl}$ - (1514)

40. $1 / 39 \mathrm{ed}+\mathrm{AD0}-20101123-20110208$ (30) 
Figure 1 Flow chart of study selection.

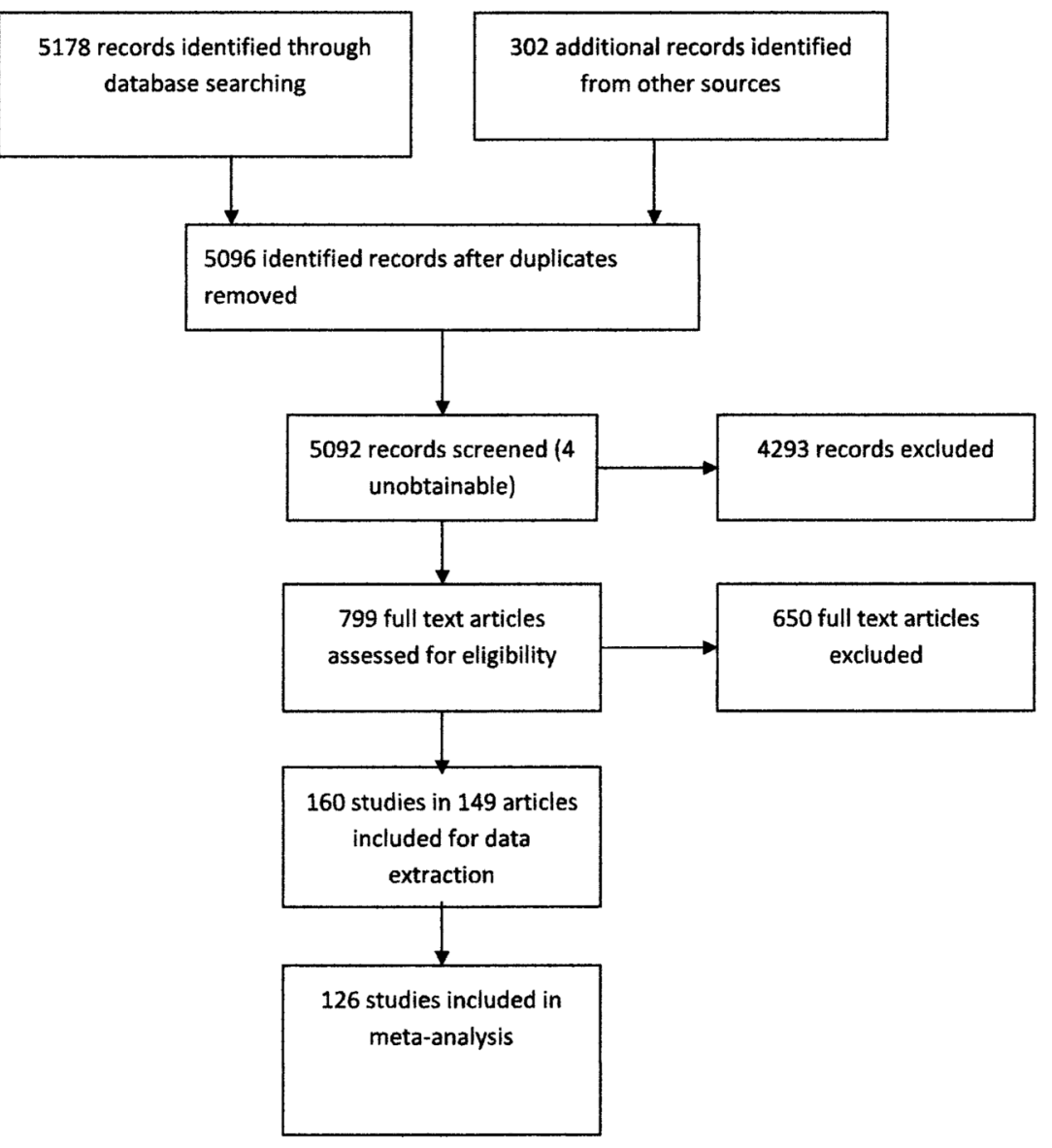

Studies were included if the design was cross-sectional, case-control, cohort, register-based or based on routinely collected data derived from a whole population and reported empirical, individual level data on the association of SES with disabling chronic conditions in childhood (box 2). Studies that were based on selected populations (eg, inner-city dwellers or minority ethnic groups only) and those not reporting results for children separately from adults were excluded as were those in which the duration or activity limitation of the condition was not specified. We excluded studies in which the disabling chronic condition was reported as a continuous variable.

Studies were assessed for quality by one reviewer (NJS) and checked by a second reviewer (CMB). Differences of opinion were settled by discussion. We extended the Newcastle-Ottawa Scales $^{7}$ to assess risk of bias for each of the five study types: cross-sectional, case-control, cohort, register-based and routinely collected data. Standard criteria for assessing risk of bias for each of the study types are shown in online supplementary appendix 1. Major confounding variables, referred to in online supplementary appendix 1, were child's age, child's sex, race/ethnicity and lone parenthood.

Types of disabling chronic conditions and SES measures Children included in the studies had a range of disabling chronic conditions characterised by duration longer than 6 months and associated limitation of normal daily activity. Conditions were grouped as follows: all-cause disabling chronic conditions; psychological disorders; intellectual disability; sensory impairments; congenital abnormalities; specific conditions, such as asthma, cerebral palsy and epilepsy; and a miscellaneous group of conditions with insufficient numbers for entry into meta-analysis (table 1). SES measures were grouped as follows: parental education level, income, occupational class, area-based SES measures, poverty, housing tenure, workless household, composite SES measures, miscellaneous measures (table 2). Low SES was defined as the most disadvantaged group for which prevalence was reported in each study.

\section{Data analysis}

\section{Quantitative data synthesis}

We extracted crude or adjusted ORs with 95\% CIs by SES measures from studies in which these were reported. Where studies reported a disabling chronic condition by more than one SES measure, we included the measure associated with the highest $O R$ in the initial meta-analysis and undertook sensitivity analysis using the SES measure with the lowest OR. For studies reporting raw data, crude ORs with $95 \%$ CIs were calculated for comparison of children with disabilities with children without disabilities. Where results were reported separately for boys and girls, ORs for all children were recalculated from raw data. For studies in which neither ORs 


\section{Box 2 Inclusion and exclusion criteria}

Inclusion

- Cross-sectional, cohort, case-control studies and those based on condition registers and routine data published between 1 January 1991 and 31 December 2013

- Studies conducted in high-income OECD countries as defined by the World Bank*

- Empirical data on the association of socioeconomic status (SES) with disabling chronic conditions in children reported

- Conditions lasting at least 6 months AND associated with limitation in normal daily activity reported

- Studies based on whole population data or samples representative of whole populations

Exclusion

- Studies published before 1991 and after 2013

- Studies conducted in countries not on the World Bank OECD high-income list*

Reviews

- Association of SES with disabling chronic conditions not reported

- Reported conditions not defined by duration AND activity limitation

- Population subgroups only reported

- Sample not representative of whole population

Mortality studies

- Studies reporting all age data with no data on children as a separate group

- Studies reporting non-individual level episode data

- Studies reporting outcomes as non-dichotomised, continuous variables

- Studies using aggregated SES measures which include major confounders of the relationship with disabling chronic conditions, such as ethnicity and lone parenthood.

* See World Bank classification of countries by income at http://data.worldbank.org/about/country-and-lending-groups

nor raw data were reported, the investigators were contacted to request data. Pooled ORs with $95 \%$ CIs for the risk of low SES were calculated using a random-effects model using the function for summary meta-analysis in StatsDirect (V.2.7.8). Heterogeneity in pooled data was estimated using the $\mathrm{I}^{2}$ statistic and risk of bias using the Egger $^{155}$ and Begg-Mazumdar tests. ${ }^{156}$ Forest plots were generated showing ORs with 95\% CIs for each study and the overall random-effects pooled estimate. For pooled estimates with a high $\mathrm{I}^{2}$ statistic, sensitivity analyses, aimed at explaining some or all of the heterogeneity, were undertaken by re-running the meta-analyses comparing studies with specific characteristics which were identified a priori as the most likely to contribute to heterogeneity (eg, geographical area of study (the USA vs the rest), studies with high vs medium/low risk of bias; studies reporting crude ORs only versus adjusted ORs; different SES measures used in same study; different age ranges).

\section{Narrative data analysis}

Studies not reporting ORs with 95\% CIs or raw data from which these could be calculated were not entered into the meta-analyses. We undertook narrative analysis of these studies. A simple count of studies with results consistent and inconsistent with the pooled estimates was made, and the latter were analysed in more detail.

\section{Role of the funding source}

The funder of the study had no role in study design, data collection, data analysis, data interpretation or writing of the report. All authors had full access to all data in the study and had final responsibility for the decision to submit for publication.

\section{RESULTS}

Our search identified 160 studies with relevant data reported in 149 papers (see figure 1 and online supplementary appendix 2). Ninety studies were cross-sectional, 25 cohort, 21 based on routine data, 16 case-control and 8 based on disease registers (see online supplementary appendix 1). The types of disabling chronic condition reported are listed in table 1 . Psychological disorders were the most frequently reported conditions (72 studies) followed by all-cause disabling chronic conditions (29 studies) and intellectual disability (25 studies). A combined total of more than 889618 children with disabling chronic conditions were included in the studies, in which sample sizes varied between 50 and 41928 607. All but one study ${ }^{63}$ reported data on both sexes, although data on the association with SES were reported separately for boys and girls in some studies. Ages of the children included in the studies were mainly between 0 and 18 years; 11 included young people aged 19-21 years. Eighty-six studies were carried out in the WHO European region (the UK 55; Finland 8; Denmark 3; Norway 3; Sweden 1; two or more Nordic countries 5; Holland 3; Germany 3; Spain 3; Italy 1; Belgium 1), 63 in the WHO region of the Americas (the USA 53; Canada 10) and 11 in the WHO Western Pacific Region (Australia 9; New Zealand 2).

Risk of bias was low in 13 studies of which 6 were based on routinely collected data, 4 case-control, 1 cohort and 2 register-based studies. No cross-sectional studies had low risk of bias. The majority (58\%) had a medium risk of bias and 53 studies had a high risk. Non-adjustment for major confounding variables was the most common source of bias affecting $75 \%$ of studies. Outcomes were parent-reported in most cross-sectional and cohort studies with only five cross-sectional and five cohort studies reporting independent blind assessment of the outcome. In the remaining three study types, $67 \%$ of cases were independently clinically identified. Insufficient information was given in five of the cross-sectional and cohort studies on the representativeness of the study sample and of the controls in four case-control studies. Denominator populations were clearly defined in all but one of the register-based and routine data-based studies (see online supplementary appendix 1). 
Table 1 Groups of disabling chronic conditions (DCC) and included conditions

\begin{tabular}{|c|c|c|c|}
\hline DCC group & $\begin{array}{l}\text { Number of } \\
\text { included studies }\end{array}$ & $\begin{array}{l}\text { Number of affected } \\
\text { children }\end{array}$ & Conditions included in the group \\
\hline $\begin{array}{l}\text { All-cause disabling } \\
\text { chronic conditions }\end{array}$ & 29 studies $^{12} 8-30$ & $\begin{array}{l}76226^{*} \text { affected } \\
\text { children }\end{array}$ & $\begin{array}{l}\text { Combined categories of all chronic } \\
\text { conditions with associated activity } \\
\text { limitation, including physical, sensory } \\
\text { and psychological disabilities or } \\
\text { long-term health problems }\end{array}$ \\
\hline Psychological disorders & 72 studies $^{11} 1618$ 31-94 & $\begin{array}{l}72277^{*} \text { affected } \\
\text { children }\end{array}$ & $\begin{array}{l}\text { All-cause psychological disorder, } \\
\text { attention deficit hyperactivity disorder, } \\
\text { autistic spectrum disorder, emotional } \\
\text { disorder, oppositional defiant } \\
\text { disorder, conduct disorder, } \\
\text { internalising and externalising } \\
\text { behaviour problems, obsessive } \\
\text { compulsive disorder, chronic fatigue } \\
\text { syndrome }\end{array}$ \\
\hline Intellectual disability & 25studies, 5260697184 95-113 & $\begin{array}{l}633235^{\star} \text { affected } \\
\text { children }\end{array}$ & $\begin{array}{l}\text { Children with } \mathrm{IQ}<70 \text { or equivalent } \\
\text { measure }-7 \text { of these studies report } \\
\text { mild and moderate/severe disability }\end{array}$ \\
\hline Sensory impairments & 12 studies $^{1151718488112114-119}$ & $\begin{array}{l}11994^{\star} \text { affected } \\
\text { children }\end{array}$ & $\begin{array}{l}\text { Hearing impairment and visual } \\
\text { impairment }\end{array}$ \\
\hline Cerebral palsy & 8 studies $^{84} 120-126$ & 16084 affected children & $\begin{array}{l}\text { Non-acquired and acquired cerebral } \\
\text { palsy }\end{array}$ \\
\hline Epilepsy & 9 studies $^{1131} 104112$ 127-131 & $\begin{array}{l}13562^{*} \text { affected } \\
\text { children }\end{array}$ & $\begin{array}{l}\text { Recurrent epileptic seizures excluding } \\
\text { febrile seizures }\end{array}$ \\
\hline Asthma & 13 studies $^{1151} 132-141$ & 6407 affected children & $\begin{array}{l}\text { Asthma with activity limitation and/or } \\
\text { asthma requiring hospital admission }\end{array}$ \\
\hline $\begin{array}{l}\text { Congenital anomalies } \\
\text { identifiable at birth }\end{array}$ & 14 studies $^{110} 142-153$ & $\begin{array}{l}41956^{\star} \text { affected } \\
\text { children }\end{array}$ & $\begin{array}{l}\text { Neural tube defects compatible with } \\
\text { life, cleft lip and palate, other } \\
\text { congenital and chromosomal } \\
\text { abnormalities }\end{array}$ \\
\hline $\begin{array}{l}\text { Miscellaneous conditions } \\
\text { (insufficient numbers for } \\
\text { meta-analysis) }\end{array}$ & 4 studies $^{85104112154}$ & 8954 children & $\begin{array}{l}\text { Crohn's disease, Down's syndrome, } \\
\text { diabetes mellitus, heart disease }\end{array}$ \\
\hline
\end{tabular}

*Indicates incomplete totals as some studies reported no data on number of participants.

\section{Quantitative data synthesis}

One hundred and twenty-six studies had data suitable for meta-analysis. Risk and pooled random-effects estimates for groups of disabling chronic conditions are shown in figures 2-9 and table 3 . The pooled ORs for the different groups of disabling chronic conditions by low SES were as follows: 1.72 for 20 studies reporting all-cause disabling chronic conditions, 1.88 for 55 studies reporting psychological disorders, 2.41 for 21 studies reporting intellectual disability, 2.20 for 13 studies reporting activity limitation or hospital admission for asthma, 1.42 for 6 studies reporting cerebral palsy, 1.41 for 13 studies of congenital abnormalities, 1.38 for 6 studies of epilepsy and 1.70 for 9 studies of sensory impairments. The $\mathrm{I}^{2}$ statistic was $>75 \%$ for all, but the pooled estimates for cerebral palsy, epilepsy and sensory impairments. Pooled estimates were available for specific psychological disorders (attention deficit hyperactivity disorder (ADHD; 1.63 (1.42 to 1.86)), conduct disorder (1.93 (1.58 to 2.38$)$ ) and emotional disorder (2.03 (1.67 to 2.47)), and for mild (3.94 (2.26 to 6.86)) and moderate/severe (2.19 (1.84 to 2.64)) intellectual disability (forest plots not shown)).

Bias indicators were non-significant for all groups of disabling chronic conditions except for psychological disorders for which the Egger test was significant ( $\mathrm{p}=0.0012)$ but not the Begg-Mazumdar test $(\mathrm{p}=0.97)$. Sensitivity analyses showed no significant differences in pooled estimates based on specific characteristics of studies for all disabling chronic condition groups except asthma and psychological disorders (see online supplementary appendix 3). The pooled OR for asthma for studies reporting crude ORs only (3.00 (95\% CI 2.89 to 3.11)) was significantly higher than that for those reporting adjusted ORs (1.75 (95\% CI 1.35 to 2.36)). For psychological disorders, the pooled OR for studies including only children $<12$ years of age was significantly higher than that for studies including older children (pooled ORs 2.48 (95\% CI 2.07 to 2.97) and 1.77 (1.55 to 2.03$)$, respectively). 
Table 2 Socioeconomic status (SES) measures

\begin{tabular}{|c|c|c|}
\hline SES measure group* & $\begin{array}{l}\text { Number of } \\
\text { studies }\end{array}$ & Specific measures included in group \\
\hline Parental education & 56 studies & $\begin{array}{l}\text { Maternal education; paternal education; highest parental educational level; } \\
\text { years of education; qualifications achieved }\end{array}$ \\
\hline Income & 49 studies & $\begin{array}{l}\text { Household income; equivalised household income using OECD method; } \\
\text { urban income }\end{array}$ \\
\hline Poverty & 42 studies & $\begin{array}{l}\text { Relationship to Federal Poverty Line (USA); }<60 \% \text { of national median income } \\
\text { (UK); receipt of social safety net benefits }\end{array}$ \\
\hline Occupational class & 37 studies & $\begin{array}{l}\text { UK Registrar General's social class; UK National Statistics Socio-economic } \\
\text { Classification; other country classifications (Finland, Denmark, Sweden, } \\
\text { Holland); Bilshen Occupational Scale (Canada) }\end{array}$ \\
\hline Area-based SES measures & 35 studies & $\begin{array}{l}\text { UK deprivation indices (Townsend; Carstairs); Acorn area classification (UK); } \\
\text { census-derived area income measures (USA and Canada); Socio-economic } \\
\text { Indicators for Area-SEIFA (Australia); inner city vs suburbs }\end{array}$ \\
\hline Housing tenure & $\begin{array}{l}11 \text { studies-all } \\
\text { UK }\end{array}$ & Rented vs owner-occupied accommodation \\
\hline Workless household & 9 studies & Households with no working adult \\
\hline $\begin{array}{l}\text { Composite individual level } \\
\text { SES measures }\end{array}$ & 7 studies & $\begin{array}{l}\text { Winkler index; occupation and education of both mothers and fathers; } \\
\text { occupation and education of both parents and household income; social } \\
\text { disadvantage index (occupation; housing tenure; car ownership) }\end{array}$ \\
\hline Other & 8 studies & $\begin{array}{l}\text { Material hardship (unable to afford essential items); debt; car ownership; } \\
\text { family affluence scale }\end{array}$ \\
\hline
\end{tabular}

\section{Narrative data analysis}

Data from 34 studies were not suitable for meta-analysis. Of the eight studies reporting all-cause disabling chronic conditions, three reported findings suggesting no association with low SES. Ford $e t a l,{ }^{26}$ based on data from the baseline study of 15 year-olds included in the prospective West of Scotland Twenty-07 study, report an association of limiting long-standing illness among boys with low
Figure 2 Risk estimates of low socioeconomic status in children with all-cause disabling chronic conditions.

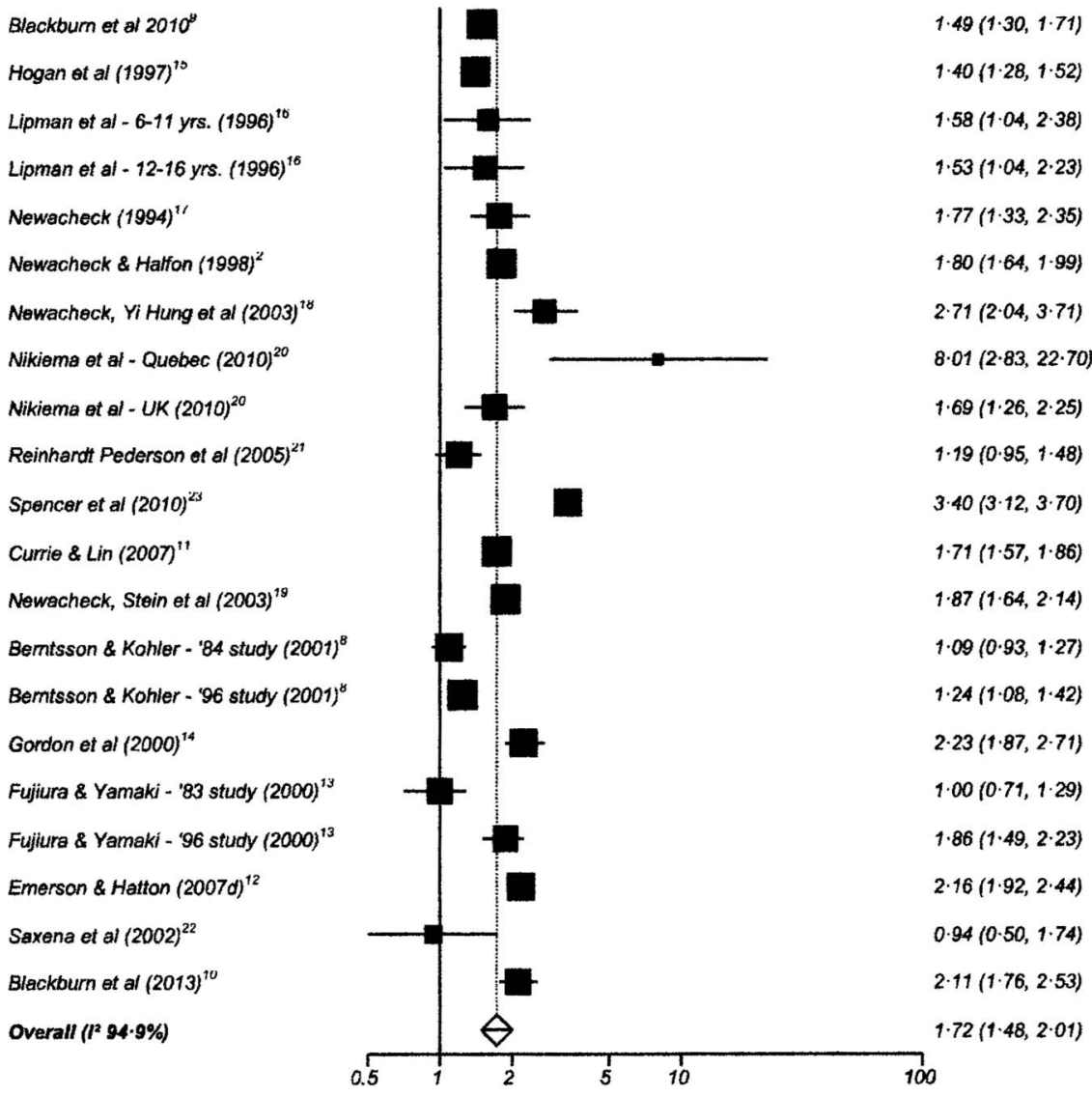




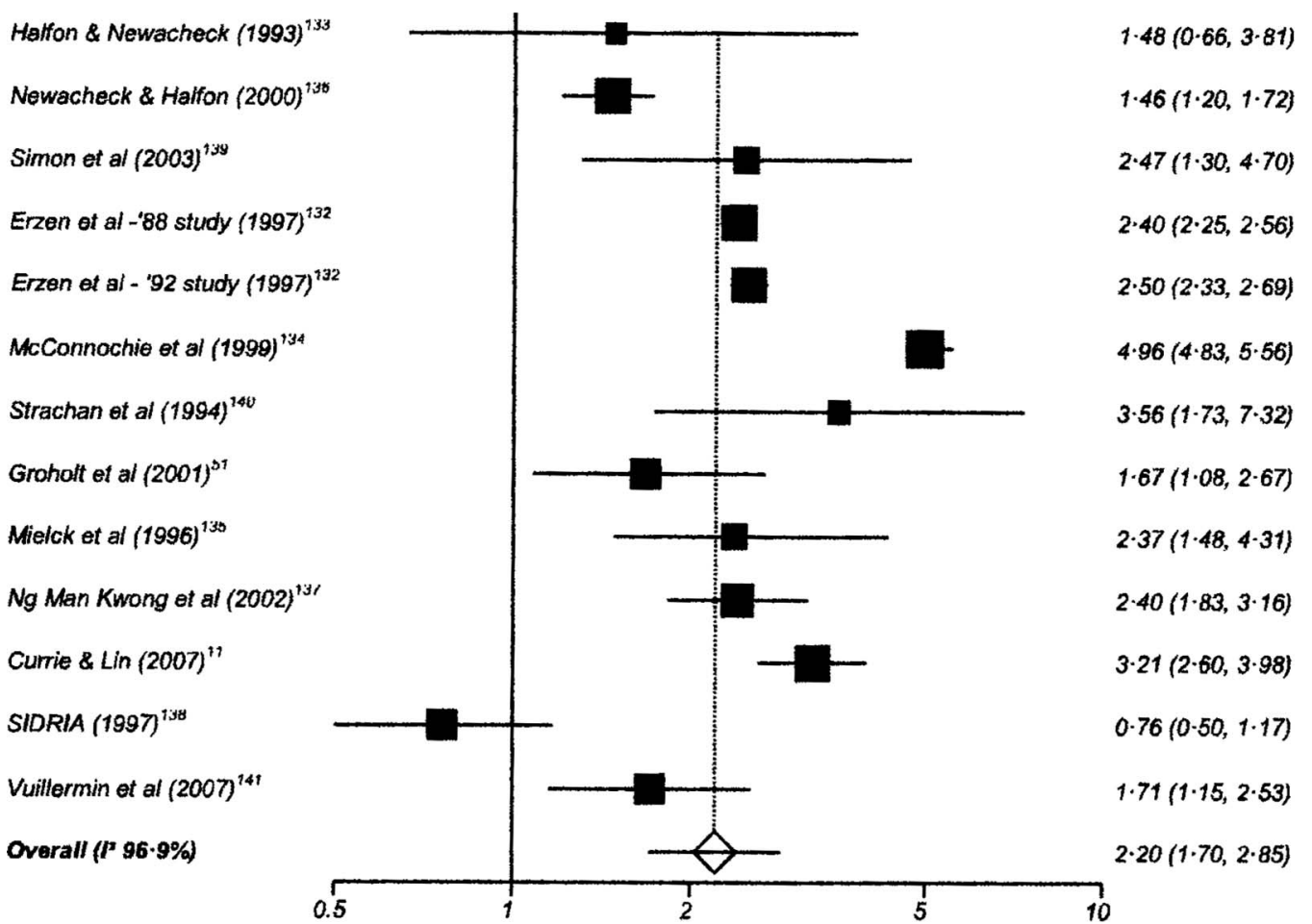

Figure 3 Risk estimates of low socioeconomic status in children with asthma.

parental social class $(\mathrm{p}<0.05)$, but not for girls. In a review article, West ${ }^{29}$ reports data on 18 year-olds from the West of Scotland Twenty-07 study showing no significant differences in prevalence of all limiting long-standing illness among either males or females by social class, but a higher prevalence among low social class boys of severe limiting long-standing illness (defined as 'quite a lot' or 'very great deal' of restriction), but not among girls. These studies both carry a high risk of bias (see online supplementary appendix 1) and the reporting of parental social class by young people may not be reliable. West and Sweeting ${ }^{30}$ reported little evidence of SES differences in limiting longstanding illness among boys and girls aged 11, 13 and 15 years in the West of Scotland 11-16 Cohort study. This study used a number of SES measures reported by parents; however, it has a high risk of bias.

Five of the studies not suitable for meta-analysis reporting on psychological disorders found no

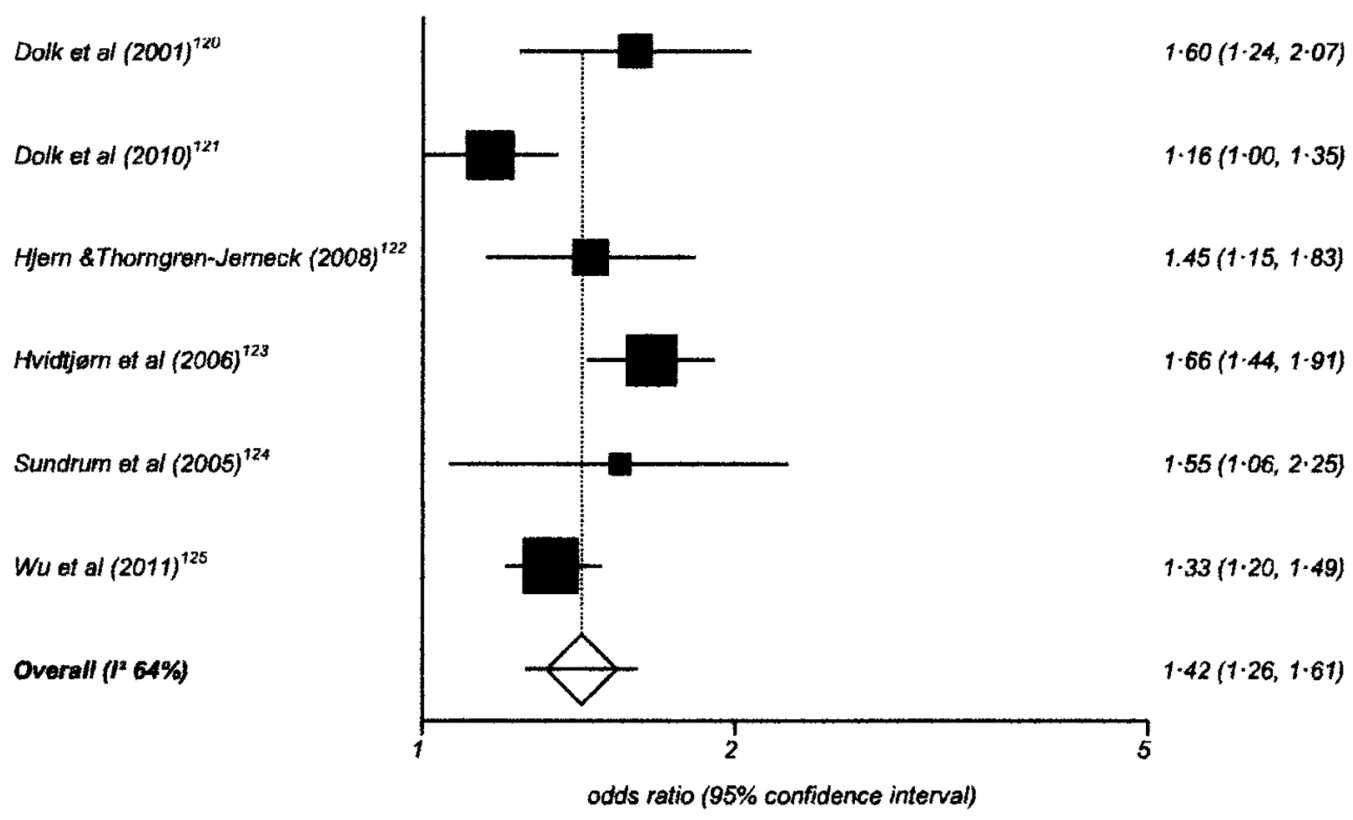

Figure 4 Risk estimates of low socioeconomic status in children with cerebral palsy. 


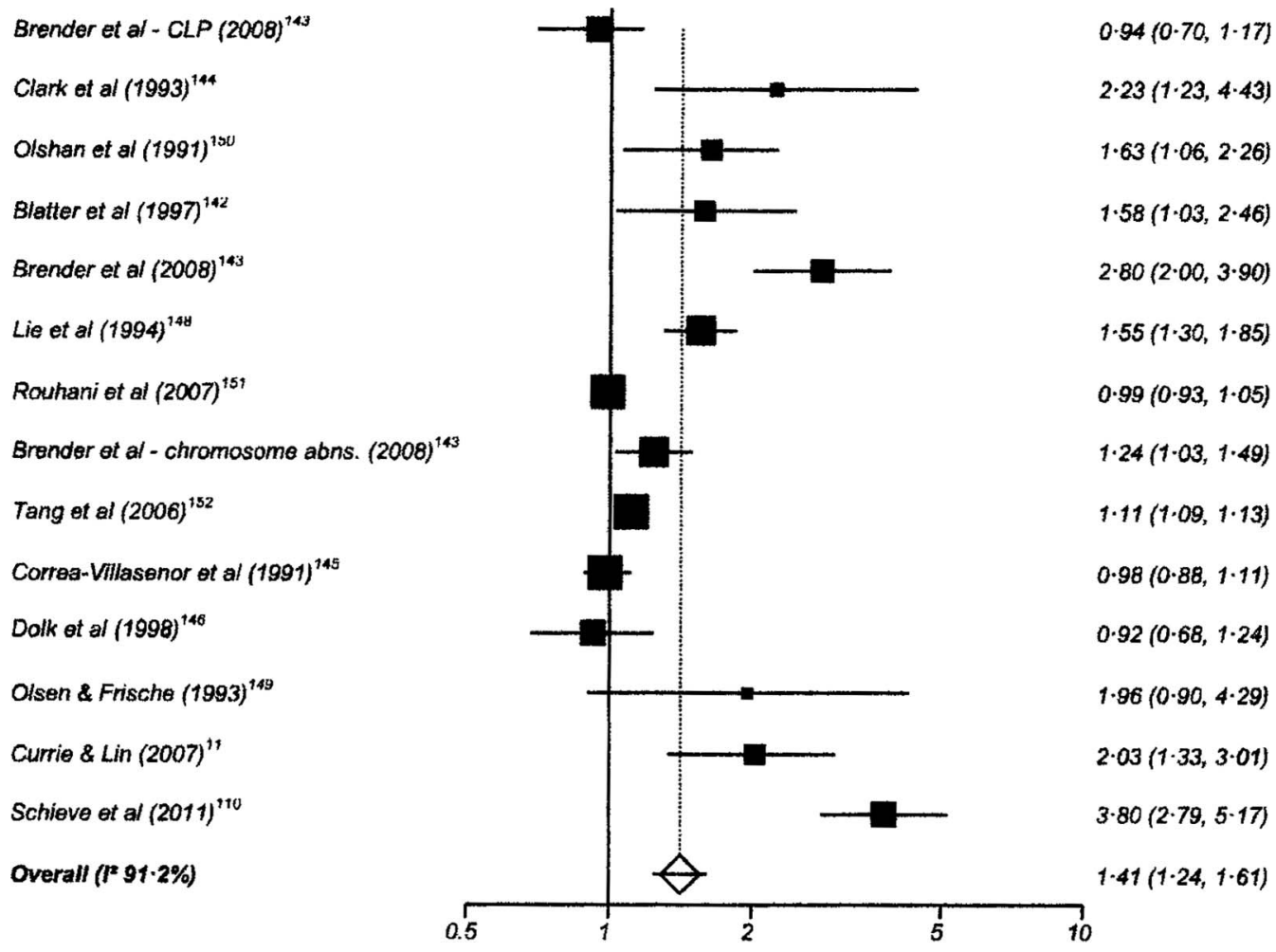

Figure 5 Risk estimates of low socioeconomic status in children with congenital abnormalities.

association with low SES. A reverse SES gradient for ADHD is reported by Hoffman $e t a l^{87}$ based on a cohort initially designed to study the association between exposure to tetrachloroethylene (PCE)-contaminated public drinking water and the risk of reproductive and developmental disorders. Exclusions from the original cohort plus no information about the attrition rate may have led to a non-representative sample for this analysis. The study has a high risk of bias. Khanam et $a l^{88}$ found no significant association of low income with ADHD among 8-year-old children enrolled in the kindergarten cohort of the Longitudinal Study of Australian Children. The regression models included many socially related variables that could be mediators of the low-income ADHD, thus suggesting the possibility of overcontrolling for SES. The study has a medium risk of bias. No association of behavioural problems at 3 years of age with SES was reported by Sonuga-Barke et $a \ell^{3}$ from a cross-sectional

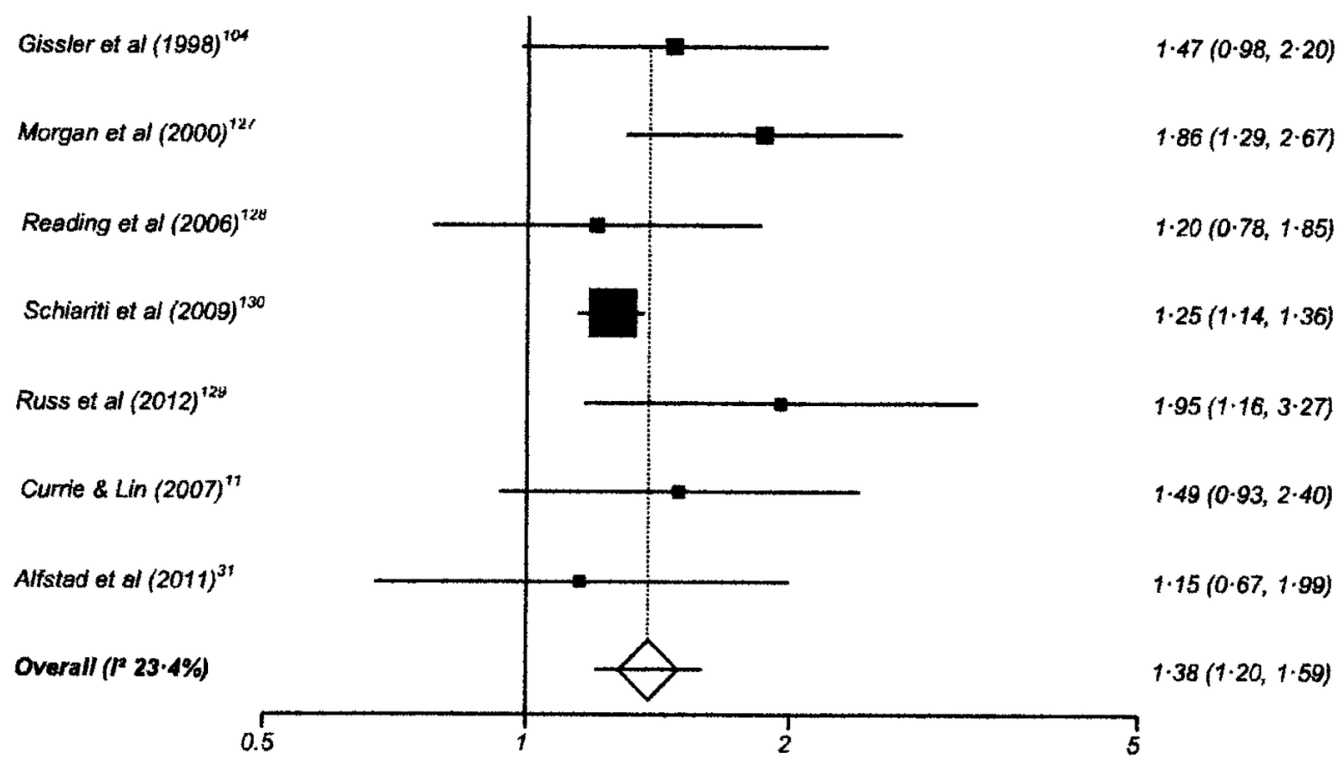

Figure 6 Risk estimates of low socioeconomic status in children with epilepsy. 


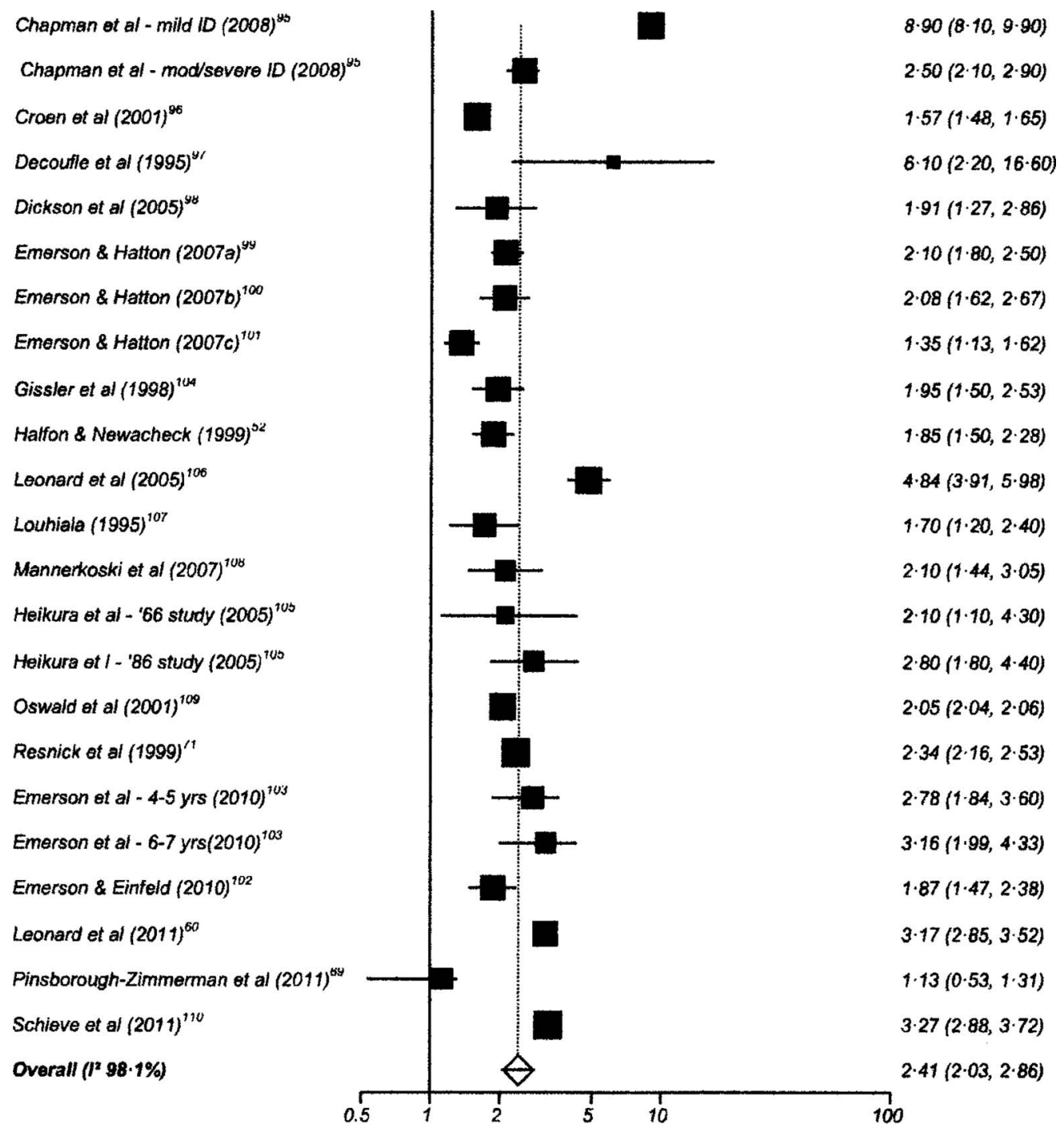

Figure 7 Risk estimates of low socioeconomic status in children with intellectual disability (ID).

study based on developmental clinics run by family doctors in an area of south England. In addition to having a high risk of bias, low SES families may have been under-represented in the sample due to socially patterned differential uptake of developmental checks at 3 years. Boyle $e t a l^{84}$ reported no significant difference in prevalence of ADHD among children aged 3-17 years by poverty or low maternal education. This study, which has a medium risk of bias, was based on a large, aggregated sample from the US National Health Interview Surveys (NHIS) for the years 1997-2008. Blackwell and Tonthat, ${ }^{33}$ and Bloom $e t a l^{55}$ reporting on samples from the NHIS for the years 1998 and 2001, respectively, also showed no association with poverty or parental education, although significant associations were noted for the years $1999^{34}$ and $2006 .^{36}$

Khanam et $a l^{88}$ and Boyle $e t a l^{84}$ reported no association of sensory impairments with low SES. As indicated above, the inclusion of many socially related variables in the regression model in Khanam's paper may have been overcontrolled for SES. By contrast, Boyle et $a l^{84} \mathrm{did}$ not control for potential confounders. Boyle et $a l^{84}$ also reported no association of cerebral palsy with either poverty or maternal education. There were no studies unsuitable for meta-analysis of intellectual disability or congenital abnormalities that reported no association of the outcome with low SES. All studies of asthma had data suitable for meta-analysis.

\section{Discussion}

This is the first systematic review and meta-analyses of studies reporting on the relationship between childhood disabling chronic conditions and low SES in highincome countries. The results of the meta-analyses show that a range of childhood disabling chronic conditions are associated with low SES.

The review shows the association of the most common childhood disabling chronic conditions with low SES. Psychological disorders and intellectual disabilities are among the most common and intractable conditions, and impacts on children, their families and health, social and education services are substantial. The odds 

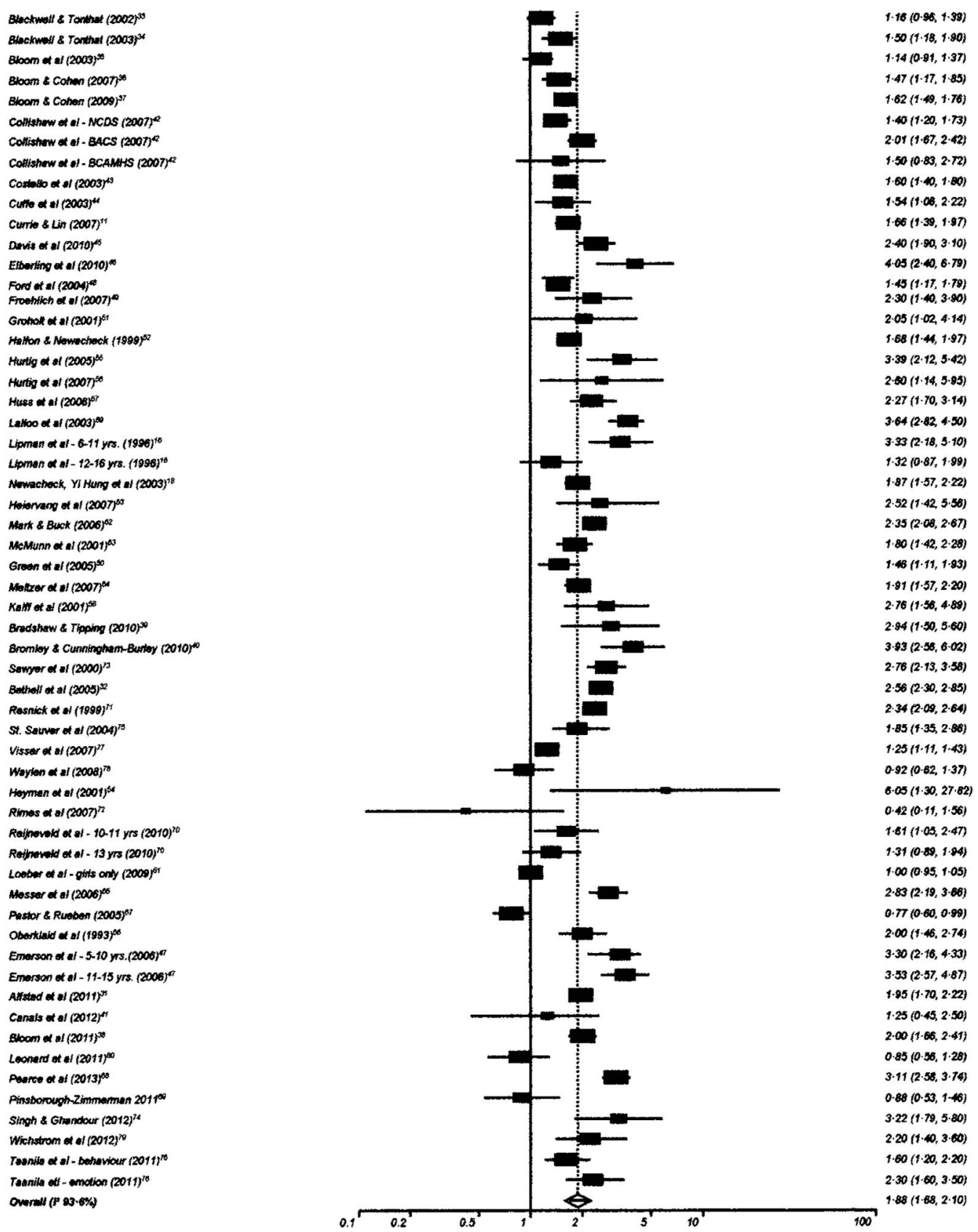

Figure 8 Risk estimates of low socioeconomic status in children with psychological disorders.

of these being reported among low SES households are around twice those for high SES households.

Asthma is one of the most prevalent chronic conditions in childhood in high-income countries. A recent systematic review and meta-analysis reported low SES associated with a higher prevalence of asthma in $63 \%$ of studies with a pooled estimate of 1.38 (95\% CI 1.37 to 1.39). ${ }^{157}$ We included only studies reporting on asthma severe enough to cause activity limitation and/or hospital admission, and found a strong association with SES. To date, the evidence on the association of cerebral palsy and epilepsy with low SES has also been unclear, and likely to be related to study methodologies. ${ }^{124} 128$ Pooled estimates for both in this review, however, support a significant association.
Confirmation of the association of disabling chronic conditions with low SES using systematic review methodology and generation of pooled estimates of risk is important. Further research, however, is needed to explain this association in high-income countries. One possible explanation is that poor social and environmental conditions in pregnancy and early childhood are on the causal pathway to childhood disabling chronic conditions. Some included papers discuss the poor social conditions that might lead to conditions, such as activitylimiting asthma, ${ }^{133}$ and the role of socially patterned problems in pregnancy in the aetiology of cerebral palsy ${ }^{120}$ and congenital abnormalities. ${ }^{145}{ }^{149}$ Questions of causality, however, can only be addressed using cohort studies with low risk of bias. The majority of studies in 


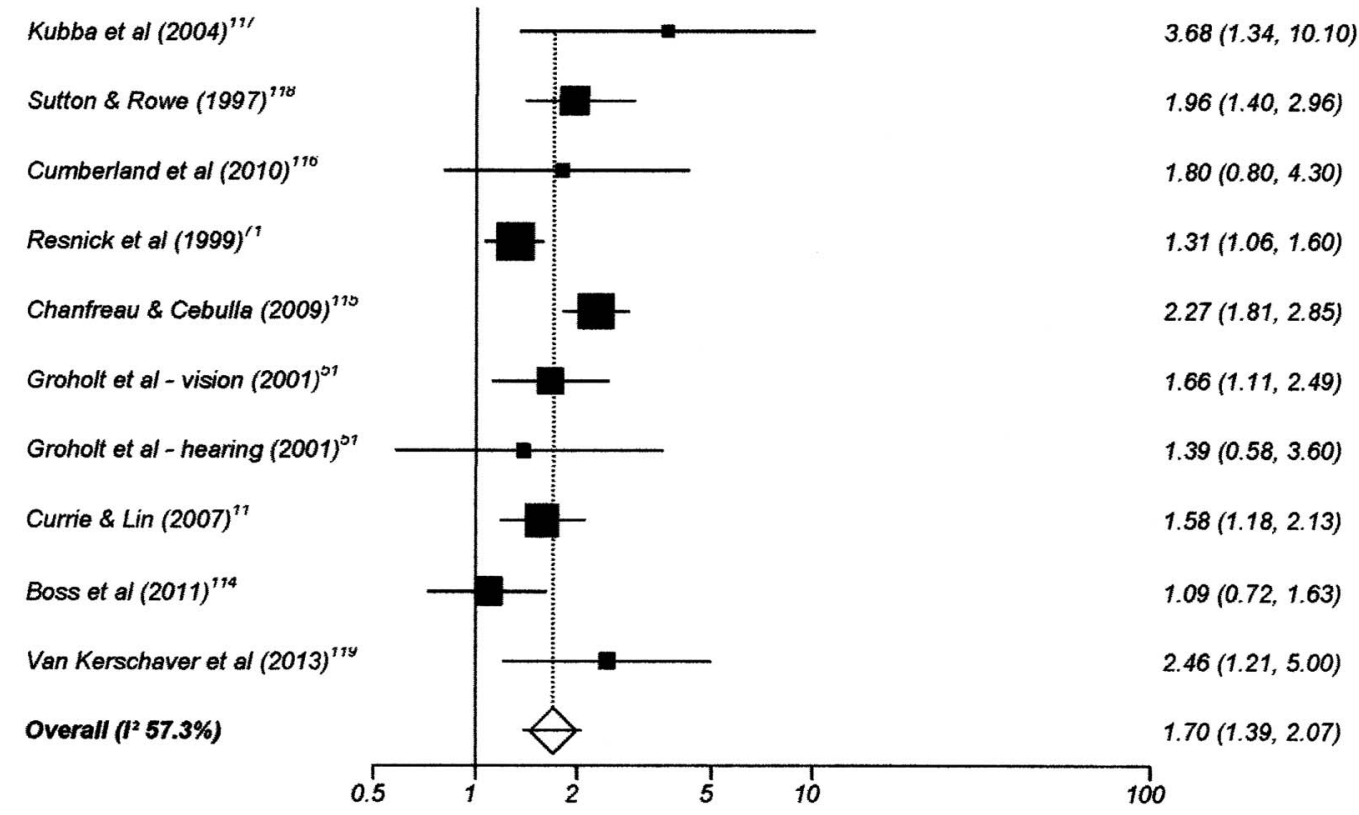

Figure 9 Risk estimates of low socioeconomic status in children with sensory disabilities.

this review were cross-sectional. Of the 21 cohort designs we identified, only 1 was assessed as having a low risk of bias. Low parental education is likely to precede the onset of a child's disabling condition and its association with a range of conditions (see online supplementary appendix) lends support to the explanation that SES is on the causal pathway. The reverse causation explanation is that caring for a child with a disabling chronic condition leads to low SES by limiting household income and increasing household costs. Anderson et $a l^{158}$ show the impact on family finances and work of having a child with intellectual and/or developmental disability.

The review has several methodological issues and limitations which should be considered when interpreting the findings. Definitions of disability vary widely as do measures used to identify those with disabilities in populations. In line with the focus of the World Report on Disability $^{3}$ and International Classification of Functioning, Disability and Health, ${ }^{159}$ we only included in this review studies reporting on conditions that were both long term and activity limiting. Therefore, studies which used broader definitions of disability were excluded, possibly limiting the scope of the review. The use of expanded MeSH terms for SES may have led to studies being missed; however, the SES measures identified (table 2) include a comprehensive range. There is no internationally agreed definition of 'low SES', as different measures are required for different purposes and are meaningful in particular national contexts. The included studies, therefore, use a variety of SES measures and this may be one of the factors contributing to the high level of heterogeneity in the pooled estimates. In sensitivity analyses, however, pooled estimates did not change significantly when different SES measures were used. Many included studies also had a high risk of bias and this is also likely to have contributed to heterogeneity. In particular, in some studies, the failure to adjust for potential confounding factors may have resulted in overestimation of the strength of the association. This was supported by the sensitivity analysis for severe asthma that showed a significantly higher pooled estimate for studies that did not adjust for confounders compared with those that did. There were no similar

Table 3 Pooled random effects estimates for low socioeconomic status by groups of disabling chronic conditions

\begin{tabular}{llll}
\hline Disabling chronic condition & Studies & OR (95\% CI) & Heterogeneity (I $^{\mathbf{2}}$ statistic) \\
\hline All-cause disabling chronic conditions & 20 & $1.72(1.48$ to 2.01$)$ & $95.0 \%(94.7 \%$ to $95.7 \%)$ \\
Psychological disorders & 55 & $1.88(1.68$ to 2.10$)$ & $93.6 \%(92.6 \%$ to $94.3 \%)$ \\
Intellectual disability & 21 & $2.41(2.03$ to 2.86$)$ & $98.1 \%(97.9 \%$ to $98.3 \%)$ \\
Activity-limitation or hospital admission for asthma & 13 & $2.20(1.87$ to 2.85$)$ & $96.9 \%(96.2 \%$ to $97.4 \%)$ \\
Cerebral Palsy & 6 & $1.42(1.26$ to 1.61$)$ & $64.0 \%(0 \%$ to $83.1 \%)$ \\
Congenital abnormalities & 13 & $1.41(1.24$ to 1.61$)$ & $91.2 \%(87.6 \%$ to $93.4 \%)$ \\
Epilepsy & 6 & $1.38(1.20$ to 1.59$)$ & $23.4 \%(0 \%$ to $67.5 \%)$ \\
Sensory impairment & 9 & $1.70(1.39$ to 2.07$)$ & $57.3 \%(0$ to $77.2 \%)$ \\
\hline
\end{tabular}


findings, however, for other conditions. As the sensitivity analyses explain little of the heterogeneity, it is likely that factors we have not been able to measure are responsible. In addition, different sources of information are used to identify a child as having a disabling chronic condition and this may also have contributed to the heterogeneity in the pooled estimates.

This systematic review and meta-analyses make an important contribution to knowledge of the association of childhood disabling chronic conditions with socioeconomic disadvantage in high-income countries. Although caution should be exercised in interpreting the findings due to unexplained heterogeneity and the high risk of bias in many studies, the review indicates that these challenging conditions are more prevalent among children in disadvantaged households in a range of high-income countries. While explanations about the causes of this association are to be found in the literature, further high-quality research in cohort studies with adequate sample sizes is required to more fully address the aetiology of the associations identified by this review.

Our findings have implications for social, economic and health policy. The higher prevalence of these conditions among socioeconomically disadvantaged children in richer nations with very different policy environments represents a major challenge to governments seeking to reduce health inequalities and promote the rights of disabled children. Reducing the association between socioeconomic disadvantage and disabling chronic conditions in childhood is likely to require multidimensional strategies. These might include those proposed in the WHO report on social determinants of health that aim to reduce socioeconomic disadvantage in the early years, ${ }^{160}$ as well as policies that ensure that households with children with disabling chronic conditions have adequate financial support and access to health, education and social care services to meet their needs.

Acknowledgements The authors thank Diane Clay and Samantha Johnson for their assistance with literature searches.

Contributors CMB, NJS and JMR designed the study. CMB was lead researcher on the project and supervised its implementation. NJS, CMB and JMR coordinated the search strategy, and jointly established the criteria for study selection, data extraction and quality assessment. JMR and NJS undertook the initial inclusion and exclusion of abstracts. NJS extracted data from potentially relevant full-text papers onto standard extraction forms which were checked by CMB. NJS planned and did the meta-analyses. NJS, CMB and JMR wrote the report. All authors reviewed the study findings, and read and approved the final version before submission.

Funding This study was funded by the Economic and Social Research Council (grant number RES-062-23-2883).

Competing interests None declared.

Provenance and peer review Not commissioned; externally peer reviewed.

Data sharing statement No additional data are available.

Open Access This is an Open Access article distributed in accordance with the terms of the Creative Commons Attribution (CC BY 4.0) license, which permits others to distribute, remix, adapt and build upon this work, for commercial use, provided the original work is properly cited. See: http:// creativecommons.org/licenses/by/4.0/

\section{REFERENCES}

1. Halfon $\mathrm{N}$, Houtrow $\mathrm{A}$, Larson $\mathrm{K}$, et al. The changing landscape of disability in childhood. Future Child 2012;22:13-42.

2. Newacheck PW, Halfon N. Prevalence and impact of disabling chronic conditions in childhood. Am J Public Health 1998;88:610-17.

3. Bank WHOW. World Report on Disability. Geneva, 2011.

4. Fauconnier J, Dickinson $\mathrm{H}$, Beckung $\mathrm{E}$, et al. Participation in life situations of 8-12 year old children with cerebral palsy: cross sectional European study. BMJ 2009;338:b1458.

5. Hjern A, Weitoft G, Lindbald F. Social adversity predicts ADHD-medication in school children: a national cohort study. Acta Paediatr 2010;99:920-4.

6. Simkiss D, Blackburn C, Mukoro M, et al. Childhood disability and socio-economic circumstances in low and middle income countries: a systematic review. BMC Pediatr 2011;11:119.

7. Wells G, Shea B, O'Connell D, et al. The Newcastle-Ottawa Scale (NOS) fo assessing the quality of nonrandomised studies in meta-analyses.Ottawa: Ottawa Health Research Institute, 1999.

8. Berntsson LT, Kohler L. Long-term illness and psychosomatic complaints in children aged 2-17 years in the five Nordic countries. Comparison between 1984 and 1996. Eur J Public Health 2001;11:35-42.

9. Blackburn CM, Spencer NJ, Read JM. Prevalence of childhood disability and the characteristics and circumstances of disabled children in the UK: secondary analysis of the Family Resources Survey. BMC Pediatr 2010;10:21.

10. Blackburn CM, Spencer NJ, Read JM. Is the onset of disabling chronic conditions in later childhood associated with exposure to social disadvantage in earlier childhood? A prospective cohort study using the ONS Longitudinal Study for England and Wales. BMC Pediatr 2013;13:101.

11. Currie J, Lin W. Chipping away at health: more on the relationship between income and child health. Health Aff 2007;26:331-44.

12. Emerson E, Hatton C. The socio-economic circumstances of children at risk of disability in Britain. Disability \& Society 2007;22:568-80.

13. Fujiura G, Yamaki K. Trends in demography of childhood poverty and disability. Exceptional Child 2000;66:187-200.

14. Gordon D, Parker R, Loughran F, et al. Disabled children in Britain a re-analysis of the OPCS disability surveys. London: The Stationery Office, 2000.

15. Hogan DP, Msall ME, Rogers ML, et al. Improved disability population estimates of functional limitation among American children aged 5-17. Matern Child Health J 1997;1:203-16.

16. Lipman EL, Offord DR, Boyle MH. What if we could eliminate child poverty? The theoretical effect on child psychosocial morbidity. Soc Psychiatry Psychiatr Epidemiol 1996;31:303-7.

17. Newacheck PW. Poverty and childhood chronic illness. Arch Pediatr Adolesc Med 1994;148:1143-9.

18. Newacheck PW, Yi Hung $Y$, Park MJ, et al. Disparities in adolescent health and health care: does socioeconomic status matter? Health Serv Res 2003;38:1235-52.

19. Newacheck PW, Stein REK, Bauman L, et al. Disparities in the prevalence of disability between black and white children. Arch Pediatr Adolesc Med 2003;157:244.

20. Nikiema B, Spencer N, Seguin L. Poverty and chronic illness in early childhood: a comparison between the United Kingdom and Quebec. Pediatrics 2010;125:e499-507.

21. Reinhardt Pedersen C, Madsen M, Kohler L. Does financial strain explain the association between children's morbidity and parental non-employment? J Epidemiol Community Health 2005;59:316-21.

22. Saxena S, Eliahoo J, Majeed A. Socioeconomic and ethnic group differences in self reported health status and use of health services by children and young people in England: cross sectional study. [Erratum appears in BMJ. 2003 Aug 9;327(7410):325]. BMJ 2002;325:520.

23. Spencer NJ, Blackburn CM, Read JM. Prevalence and social patterning of limiting long-term illness/disability in children and young people under the age of 20 years in 2001: UK census-based cross-sectional study. Child Care Health Dev 2010;36:566-73.

24. Cooper $\mathrm{H}$, Arber S, Smaje C. Social class or deprivation? Structural factors and children's limiting longstanding illness in the 1990s. Sociol Health IIIn 1998;20:289-311.

25. Currie J, Stabile M. Socioeconomic status and child health: why is the relationship stronger for older children? Am Econ Rev 2003;93:1813-23.

26. Ford G, Ecob R, Hunt K, et al. Patterns of class inequality in health through the lifespan: class gradients at 15, 35 and 55 years in the west of Scotland. Soc Sci Med 1994:39:1037-50.

27. Grundy E. Disability in Great Britain: results from the $1996 / 97$ disability follow-up to the family resources survey. London: 
Department of Social Security, Corporate Document Services, 1999.

28. Maskill C, Hodges I, Burns P, et al. Living with disability in New Zealand. A descriptive analysis of results from the 2001 Household Disability Survey and the 2001 Disability Survey of Residential Facilities. Wellington, New Zealand: Ministry of Health, 2004.

29. West P. Health inequalities in the early years: is there equalisation in youth? Soc Sci Med 1997;44:833-58.

30. West $P$, Sweeting $H$. Evidence on equalisation in health in youth from the West of Scotland. Soc Sci Med 2004;59:13-27.

31. Alfstad KA, Clench-Aas J, Van Roy B, et al. Psychiatric symptoms in Norwegian children with epilepsy aged 8-13 years: effects of age and gender? Epilepsia 2011;52:1231-8.

32. Bethell C, Read D, Blumbe S. Mental health in the United States: health care and well being of children with chronic emotional, behavioral, or developmental problems-United States, 2001. MMWR Morb Mortal Wkly Rep, 2005. http://www.cdc.gov/mmwr/ preview $/ \mathrm{mmwrhtml} / \mathrm{mm} 5439 \mathrm{a3}$.htm (accessed).

33. Blackwell DL, Tonthat L. Summary health statistics for U.S. children: National Health Interview Survey, 1998. Vital Health Stat 2002;(208):1-46.

34. Blackwell DL, Tonthat L. Summary health statistics for U.S. children: National Health Interview Survey, 1999. Vital Health Stat 2003;(210):1-50.

35. Bloom B, Cohen RA, Vickerie JL, et al. Summary health statistics for U.S. children: National Health Interview Survey, 2001. Vital Health Stat 2003;(216):1-54.

36. Bloom B, Cohen RA. Summary health statistics for U.S. children: National Health Interview Survey, 2006. Vital Health Stat 2007; (234):1-79.

37. Bloom B, Cohen RA, Freeman G. Summary health statistics for U.S. children: National Health Interview Survey, 2008. Vital Health Stat 2009;(244):1-81

38. Bloom B, Cohen RA, Freeman G. Summary health statistics for U.S. children: National Health Interview Survey, 2010. Vital Health Stat $2011 ;(250): 1-80$.

39. Bradshaw P, Tipping S. GROWING UP IN SCOTLAND: children's social, emotional and behavioural characteristics at entry to primary school. Edinburgh: The Scottish Government, 2010:60.

40. Bromley C, Cunningham-Burley S. Growing up in Scotland: health inequalities in the early years. Edinburgh: The Scottish Government; 2010.

41. Canals J, Hernandez-Martinez C, Cosi S, et al. The epidemiology of obsessive-compulsive disorder in Spanish school children. $J$ Anxiety Disord 2012;26:746-52.

42. Collishaw S, Goodman R, Pickles A, et al. Modelling the contribution of changes in family life to time trends in adolescent conduct problems. Soc Sci Med 2007;65:2576-87.

43. Costello EJ, Compton SN, Keeler G, et al. Relationships between poverty and psychopathology: a natural experiment. JAMA 2003;290:2023-9.

44. Cuffe SP, Moore CG, McKeown RE. Prevalence and correlates of ADHD symptoms in the national health interview survey. J Atten Disord 2005;9:392-401.

45. Davis E, Sawyer MG, Lo SK, et al. Socioeconomic risk factors for mental health problems in 4-5-year-old children: Australian Population Study. Acad Pediatr 2010;10:41-7.

46. Elberling $\mathrm{H}$, Linneberg $\mathrm{A}$, Olsen $\mathrm{EM}$, et al. The prevalence of SDQ-measured mental health problems at age 5-7 years and identification of predictors from birth to preschool age in a Danish birth cohort: the Copenhagen Child Cohort 2000. Eur Child Adolesc Psychiatry 2010;19:725-35.

47. Emerson E, Graham H, Hatton C. Household income and health status in children and adolescents in Britain. Eur J Public Health 2006;16:354-60.

48. Ford T, Goodman R, Meltzer H. The relative importance of child, family, school and neigbourhood correlates of childhood psychiatric disorder. Soc Psychiatry Psychiatr Epidemiol 2004:39:487-96.

49. Froehlich TE, Lanphear BP, Epstein JN, et al. Prevalence, recognition, and treatment of attention-deficit/hyperactivity disorder in a national sample of US children. Arch Pediatr Adolesc Med 2007;161:857-64.

50. Green H, Executive SS. Mental health of children and young people in Great Britain, 2004. Palgrave Macmillan, 2005.

51. Groholt EK, Stigum $\mathrm{H}$, Nordhagen $\mathrm{R}$, et al. Children with chronic health conditions in the Nordic countries in 1996-Influence of socio-economic factors. Ambul Child Health 2001;7:177-89.

52. Halfon N, Newacheck PW. Prevalence and impact of parent-reported disabling mental health conditions among U.S. children. J Am Acad Child Adolesc Psychiatry 1999;38:600-9; discussion 10-3.

53. Heiervang E, Stormark KM, Lundervold AJ, et al. Psychiatric disorders in Norwegian 8-to 10-year-olds: an epidemiological survey of prevalence, risk factors, and service use. J Am Acad Child Adolesc Psychiatry 2007;46:438-47.

54. Heyman I, Fombonne E, Simmons $\mathrm{H}$, et al. Prevalence of obsessive-compulsive disorder in the British nationwide survey of child mental health. Br J Psychiatry 2001;179:324-9.

55. Hurtig T, Taanila A, Ebeling $\mathrm{H}$, et al. Attention and behavioural problems of Finnish adolescents may be related to the family environment. Eur Child Adolesc Psychiatry 2005;14:471-8.

56. Hurtig T, Ebeling H, Taanila A, et al. ADHD and comorbid disorders in relation to family environment and symptom severity. Eur Child Adolesc Psychiatry 2007;16:362-9.

57. Huss M, Holling H, Kurth B-M, et al. How often are German children and adolescents diagnosed with ADHD? Prevalence based on the judgment of health care professionals: results of the German health and examination survey (KiGGS). Eur Child Adolesc Psychiatry 2008;17(Suppl 1):52-8.

58. Kalff AC, Kroes M, Vles JS, et al. Neighbourhood level and individual level SES effects on child problem behaviour: a multileve analysis. J Epidemiol Community Health 2001:55:246-50.

59. Lalloo R, Sheiham A, Nazroo JY. Behavioural characteristics and accidents: findings from the Health Survey for England, 1997. Accid Anal Prev 2003;35:661-7.

60. Leonard H, Glasson E, Nassar N, et al. Autism and intellectual disability are differentially related to sociodemographic background at birth. PLOS ONE 2011;6:e17875.

61. Loeber R, Hipwell A, Battista D, et al. Intergenerational transmission of multiple problem behaviors: prospective relationships between mothers and daughters. J Abnorm Child Psychol 2009;37:1035-48.

62. Marks GB, Correll PK, Williamson M. Asthma in Australia 2005 Med J Aust 2005;183:445-6.

63. McMunn AM, Nazroo JY, Marmot MG, et al. Children's emotional and behavioural well-being and the family environment: findings from the Health Survey for England. Soc Sci Med 2001;53:423-40.

64. Meltzer H, Vostanis P, Goodman R, et al. Children's perceptions of neighbourhood trustworthiness and safety and their mental health. $J$ Child Psychol Psychiatry 2007;48:1208-13.

65. Messer J, Goodman R, Rowe R, et al. Preadolescent conduct problems in girls and boys. J Am Acad Child Adolesc Psychiatry 2006;45:184-91.

66. Oberklaid F, Sanson A, Pedlow R, et al. Predicting preschool behavior problems from temperament and other variables in infancy. Pediatrics 1993;91:113-20.

67. Pastor PN, Reuben CA. Racial and ethnic differences in ADHD and LD in young school-age children: parental reports in the National Health Interview Survey. Public Health Rep 2005;120:383-92.

68. Pearce A, Lewis $\mathrm{H}$, Law $\mathrm{C}$. The role of poverty in explaining health variations in 7-year-old children from different family structures: findings from the UK Millennium Cohort Study. J Epidemiol Community Health 2013;67:181-9.

69. Pinborough-Zimmerman J, Bilder D, Bakian A, et al. Sociodemographic risk factors associated with autism spectrum disorders and intellectual disability. Autism Res 2011;4:438-48.

70. Reijneveld SA, Veenstra R, de Winter AF, et al. Area deprivation affects behavioral problems of young adolescents in mixed urban and rural areas: the TRAILS study. J Adolesc Health 2010:46:189-96.

71. Resnick MB, Gueorguieva RV, Carter RL, et al. The impact of low birth weight, perinatal conditions, and sociodemographic factors on educational outcome in kindergarten. Pediatrics 1999;104:e74.

72. Rimes KA, Goodman R, Hotopf M, et al. Incidence, prognosis, and risk factors for fatigue and chronic fatigue syndrome in adolescents: a prospective community study. Pediatrics 2007;119:e603-e9.

73. Sawyer MG, Arney FM, Baghurst $P$, et al. The mental health of young people in Australia. Canberra: Commonwealth Department of Health and Aged Care, 2000.

74. Singh GK, Ghandour RM. Impact of neighborhood social conditions and household socioeconomic status on behavioral problems among US children. Matern Child Health J 2012;16(Suppl 1): S158-69.

75. St Sauver JL, Barbaresi WJ, Katusic SK, et al. Early life risk factors for attention-deficit/hyperactivity disorder: a population-based cohort study. Mayo Clin Proc 2004;79:1124-31.

76. Taanila A, Yliherva A, Kaakinen M, et al. An epidemiological study on Finnish school-aged children with learning difficulties and behavioural problems. Int J Circumpolar Health 2011;70:59-71. 
77. Visser SN, Lesesne CA, Perou R. National estimates and factors associated with medication treatment for childhood attention-deficit/ hyperactivity disorder. Pediatrics 2007;119(Suppl 1):S99-106.

78. Waylen A, Ford T, Goodman R, et al. Can early intake of dietary omega-3 predict childhood externalizing behaviour? Acta Paediatr 2009;98:1805-8

79. Wichstrom L, Berg-Nielsen TS, Angold A, et al. Prevalence of psychiatric disorders in preschoolers. J Child Psychol Psychiatry 2012;53:695-705.

80. Akinbami LJ, Liu X, Pastor PN, et al. Attention deficit hyperactivity disorder among children aged 5-17 years in the United States, 1998-2009. NCHS Data Brief 2011;(70):1-8.

81. Andres MA, Catala MA, Gomez-Beneyto M. Prevalence, comorbidity, risk factors and service utilisation of disruptive behaviour disorders in a community sample of children in Valencia (Spain). Soc Psychiatry Psychiatr Epidemiol 1999;34:175-9.

82. Apouey B, Geoffard PY. Family income and child health in the UK. $J$ Health Econ 2013;32:715-27.

83. Barnes M, Chanfreau J, Tomaszewski W. Growing up in Scotland: the circumstances of persistently poor children summary report. Scottish Government; 2010.

84. Boyle CA, Boulet S, Schieve LA, et al. Trends in the prevalence of developmental disabilities in US children, 1997-2008. Pediatrics 2011;127:1034-42.

85. Currie A, Shields MA, Price SW. The child health/family income gradient: evidence from England. J Health Econ 2007;26:213-32.

86. Dopfner M, Breuer D, Wille N, et al. BELLA study group. How often do children meet ICD-10/DSM-IV criteria of attention deficit-/ hyperactivity disorder and hyperkinetic disorder? Parent-based prevalence rates in a national sample-results of the BELLA study. Eur Child Adolesc Psychiatry 2008;17(Suppl 1):59-70.

87. Hoffman K, Webster TF, Weinberg JM, et al. Spatial analysis of learning and developmental disorders in upper Cape Cod Massachusetts using generalized additive models. Int $J$ Health Geogr 2010;9:7

88. Khanam R, Nghiem HS, Connelly LB. Child health and the income gradient: evidence from Australia. J Health Econ 2009;28:805-17.

89. Meltzer H, Gatward R, Corbin T, et al., Statistics DOfN. Persistence, onset, risk factors and outcomes of childhood mental disorders: TSO London; 2003.

90. Miech RA, Caspi A, Moffitt TE, et al. Low socioeconomic status and mental disorders: a longitudinal study of selection and causation during young adulthood 1. AJS 1999;104:1096-131.

91. Ogundele MO, De Doysa R. Is ADHD a disease of affluence? A local authority experience in north-west of England. Arch Dis Child 2011;96:A25-6.

92. Simpson GA, Barbara Bloom M, Cohen RA, et al. US children with emotional and behavioral difficulties: data from the 2001, 2002, and 2003 National Health Interview Surveys. Infants Young Child 2005;12:13.

93. Sonuga-Barke E, Stevenson J, Thompson MJ. Mental health of preschool children and their mothers in a mixed urban/rural population. II. Family and maternal factors and child behaviour. $\mathrm{Br} J$ Psychiatry 1996;168:21-5.

94. Wade TJ, Pevalin DJ, Brannigan A. The clustering of severe behavioural, health and educational deficits in Canadian children: preliminary evidence from the National Longitudinal Survey of Children and Youth. Can J Public Health 1999:90:253-9.

95. Chapman DA, Scott KG, Stanton-Chapman TL. Public health approach to the study of mental retardation. Am J Ment Retard 2008;113:102-16.

96. Croen LA, Grether JK, Selvin S. The epidemiology of mental retardation of unknown cause. Pediatrics 2001;107:E86.

97. Decoufle $\mathrm{P}$, Boyle CA. The relationship between maternal education and mental retardation in 10-year-old children. Ann Epidemiol 1995;5:347-53.

98. Dickson K, Emerson E, Hatton C. Self-reported anti-socia behaviour: prevalence and risk factors amongst adolescents with and without intellectual disability. J Intellect Disabil Res 2005;49(Pt 11):820-6.

99. Emerson E, Hatton C. Mental health of children and adolescents with intellectual disabilities in Britain. $\mathrm{Br} J$ Psychiatry 2007;191:493-9.

100. Emerson E, Hatton C. Contribution of socioeconomic position to health inequalities of British children and adolescents with intellectual disabilities. Am J Ment Retard 2007;112:140-50.

101. Emerson E, Hatton C. Poverty, socioeconomic position, social capital and the health of children and adolescents with intellectual disabilities in Britain: a replication. J Intellect Disabili Research 2007;51:866-74.
102. Emerson E, Einfeld S. Emotional and behavioural difficulties in young children with and without developmental delay: a bi-national perspective. J Child Psychol Psychiatry 2010;51:583-93.

103. Emerson E, Shahtahmasebi S, Lancaster G, et al. Poverty transitions among families supporting a child with intellectual disability. J Intellect Dev Disabil 2010;35:224-34.

104. Gissler M, Rahkonen O, Jarvelin MR, et al. Social class differences in health until the age of seven years among the Finnish 1987 birth cohort. Soc Sci Med 1998;46:1543-52.

105. Heikura U, Taanila A, Hartikainen AL et al. Variations in prenata sociodemographic factors associated with intellectual disability: a study of the 20-year interval between two birth cohorts in Northern Finland. Am J Epidemiol 2008;167:169-77.

106. Leonard H, Petterson B, De Klerk N, et al. Association of sociodemographic characteristics of children with intellectual disability in Western Australia. Soc Sci Med 2005;60:1499-513.

107. Louhiala P. Risk indicators of mental retardation: changes between 1967 and 1981. Dev Med Child Neurol 1995;37:631-6.

108. Mannerkoski MK, Aberg LE, Autti TH, et al. Newborns at risk for special education placement: a population-based study. Eur $J$ Paediatr Neurol 2007;11:223-31.

109. Oswald DP, Coutinho MJ, Best AM, et al. Impact of sociodemographic characteristics on the identification rates of minority students as having mental retardation. Ment Retard 2001;39:351-67.

110. Schieve LA, Boulet SL, Kogan MD, et al. A population-based assessment of the health, functional status, and consequent family impact among children with Down syndrome. Disabil Health $J$ 2011;4:68-77.

111. Anderson CJ, Vogel LC. Employment outcomes of adults who sustained spinal cord injuries as children or adolescents. Arch Phys Med Rehabil 2002;83:791-801.

112. Case A, Lubotsky D, Paxson C. Economic status and health in childhood: the origins of the gradient. Am Econ Rev 2002;92:1308-34

113. Emerson E, Robertson J, Wood J. Emotional and behavioural needs of children and adolescents with intellectual disabilities in an urban conurbation. J Intellect Disabil Res 2005;49:16-24.

114. Boss EF, Niparko JK, Gaskin DJ, et al. Socioeconomic disparities for hearing-impaired children in the United States. Laryngoscope 2011;121:860-6.

115. Chanfreau J, Cebulla A. Educational attainment of blind and partially sighted pupils. London: Royal National Institute for the Blind, 2009.

116. Cumberland PM, Pathai S, Rahi JS; Millennium Cohort Study Child Health G. Prevalence of eye disease in early childhood and associated factors: findings from the millennium cohort study. Ophthalmology 2010;117:2184-90.e1-3.

117. Kubba H, MacAndie C, Ritchie K, et al. Is deafness a disease of poverty? The association between socio-economic deprivation and congenital hearing impairment. Int J Audiol 2004;43:123-5.

118. Sutton GJ, Rowe SJ. Risk factors for childhood sensorineural hearing loss in the Oxford region. Br J Audiol 1997;31:39-54.

119. Van Kerschaver E, Boudewyns AN, Declau F, et al. Socio-demographic determinants of hearing impairment studied in 103,835 term babies. Eur J Public Health 2013;23:55-60.

120. Dolk H, Pattenden S, Johnson A. Cerebral palsy, low birthweight and socio-economic deprivation: inequalities in a major cause of childhood disability. Paediatr Perinat Epidemiol 2001;15:359-63.

121. Dolk H, Pattenden S, Bonellie S, et al. Socio-economic inequalities in cerebral palsy prevalence in the United Kingdom: a registerbased study. Paediatr Perinat Epidemiol 2010;24:149-55.

122. Hjern A, Thorngren-Jerneck K. Perinatal complications and socio-economic differences in cerebral palsy in Sweden-a national cohort study. BMC Pediatr 2008;8:49.

123. Hvidtjorn D, Grove J, Schendel DE, et al. Cerebral palsy among children born after in vitro fertilization: the role of preterm deliverya population-based, cohort study. Pediatrics 2006;118:475-82.

124. Sundrum $\mathrm{R}$, Wallace $\mathrm{A}$, Logan $\mathrm{S}$, et al. Cerebral palsy and socio-economic status: a retrospective cohort study. Arch Dis Child 2005;90:15-9.

125. Wu YW, Xing G, Fuentes-Afflick E, et al. Racial, ethnic, and socioeconomic disparities in the prevalence of cerebral palsy. Pediatrics 2011;127:e674-81.

126. Yeargin-Allsopp M, Van Naarden Braun K, Doernberg NS, et al. Prevalence of cerebral palsy in 8-year-old children in three areas of the United States in 2002: a multisite collaboration. Pediatrics 2008;121:547-54.

127. Kozyrskyj AL, Prasad AN. The burden of seizures in Manitoba children: a population-based study. Can J Neurol Sci 2004;31:48-52. 
128. Morgan CLI, Ahmed A, Kerr MP. Social deprivation and prevalence of epilepsy and associated health usage. J Neurol Neurosurg Psychiatry 2000;69:13-17.

129. Reading R, Haynes R, Beach R. Deprivation and incidence of epilepsy in children. Seizure 2006;15:190-3.

130. Russ SA, Larson K, Halfon N. A national profile of childhood epilepsy and seizure disorder. Pediatrics 2012;129:256-64.

131. Schiariti V, Farrell K, Hoube JS, et al. Period prevalence of epilepsy in children in BC: a population-based study. Can J Neurol Sci 2009;36:36-41.

132. Erzen D, Carriere KC, Dik N, et al. Income level and asthma prevalence and care patterns. Am J Respir Crit Care Med 1997;155:1060-5.

133. Halfon N, Newacheck PW. Childhood asthma and poverty: differential impacts and utilization of health services. Pediatrics 1993;91:56-61.

134. McConnochie KM, Russo MJ, McBride JT, et al. Socioeconomic variation in asthma hospitalization: excess utilization or greater need? Pediatrics 1999;103:e75.

135. Mielck A, Reitmeir P, Wjst M. Severity of childhood asthma by socioeconomic status. Int J Epidemiol 1996;25:388-93.

136. Newacheck PW, Halfon N. Prevalence, impact, and trends in childhood disability due to asthma. Arch Pediatr Adolesc Med 2000;154:287-93.

137. Ng Man Kwong G, Das C, Proctor AR, et al. Diagnostic and treatment behaviour in children with chronic respiratory symptoms: relationship with socioeconomic factors. Thorax 2002;57:701-4

138. SIDRA. Asthma and respiratory symptoms in 6-7 yr old Italian children: gender, latitude, urbanization and socioeconomic factors. SIDRIA (Italian Studies on Respiratory Disorders in Childhood and the Environment). Eur Respir J 1997;10:1780-6.

139. Simon PA, Zeng Z, Wold CM, et al. Prevalence of childhood asthma and associated morbidity in Los Angeles County: impacts of race/ethnicity and income. J Asthma 2003;40:535-43.

140. Strachan DP, Anderson HR, Limb ES, et al. A national survey of asthma prevalence, severity, and treatment in Great Britain. Arch Dis Child 1994;70:174-8.

141. Vuillermin PJ, South M, Carlin JB, et al. Asthma among school children in the Barwon region of Victoria. Med J Aust 2007;187:221-4.

142. Blatter BM, Hermens R, Bakker M, et al. Paternal occupational exposure around conception and spina bifida in offspring. $\mathrm{Am} \mathrm{J} \mathrm{Ind}$ Med 1997;32:283-91.

143. Brender JD, Suarez L, Langlois PH. Parental occupation, Hispanic ethnicity, and risk of selected congenital malformations in offspring Ethn Dis 2008;18:218-24.

144. Clark J, Mossey P, Sharp L, et al. Socioeconomic status and orofacial clefts in Scotland, 1989 to 1998. Cleft Palate Craniofac J 2003;40:481-5.
145. Correa-Villaseñor A, McCarter R, Downing J, et al. White-black differences in cardiovascular malformations in infancy and socioeconomic factors. Am J Epidemiol 1991;134:393-402.

146. Dolk H, Busby A, Armstrong B, et al. Geographical variation in anophthalmia and microphthalmia in England, 1988-94 Commentary: clustering of anophthalmia and microphthalmia is not supported by the data. BMJ 1998;317:905-10.

147. Farley TF, Hambidge SJ, Daley MF. Association of low maternal education with neural tube defects in Colorado, 1989-1998. Public Health 2002;116:89-94.

148. Lie $\mathrm{H}$, Borjeson $\mathrm{M}$, Lagerkvist $\mathrm{B}$, et al. Children with myelomeningocele the impact of disability on family dynamics and social conditions. A Nordic study. Dev Med Child Neurol 1994;36:1000-9.

149. Olsen J, Frische G. Social differences in reproductive health. Scand J Public Health 1993;21:90-7. NS-include

150. Olshan AF, Teschke K, Baird PA. Paternal occupation and congenital anomalies in offspring. Am J Ind Med 1991;20:447-75

151. Rouhani P, Fleming L, Fraas J, et al. Pilot study of socioeconomic class, nutrition and birth defects in Spain. Matern Child Health $J$ 2007;11:403-5.

152. Tang $\mathrm{Y}, \mathrm{Ma} \mathrm{C}-\mathrm{X}$, Cui $\mathrm{W}$, et al. The risk of birth defects in multiple births: a population-based study. Matern Child Health $J$ 2006;10:75-81.

153. Friel JK, Frecker M, Fraser FC. Nutritional patterns of mothers of children with neural tube defects in Newfoundland. Am J Med Genet 1995;55:195-9.

154. Ponsonby A-L, Catto-Smith AG, Pezic A, et al. Association between early-life factors and risk of child-onset Crohn's disease among Victorian children born 1983-1998: a birth cohort study. Inflamm Bowel Dis 2009;15:858-66.

155. Egger M, Davey Smith G, Schneider M, et al. Bias in metaanalysis detected by a simple graphical test. BMJ 1997;315:629-34.

156. Begg C, Muzumdar M. Operating characteristics of a rank correlation test for publication bias. Biometrics 1997;50: 1088-101.

157. Uphoff $\mathrm{E}$, Cabieses $\mathrm{B}$, Pinart $\mathrm{M}$, et al. A systematic review of socioeconomic position in relation to asthma and allergic diseases. Eur Respir J 2015;46:364-74

158. Anderson L, Larson S, Lakin C, et al. Children with disabilities: social roles and family impacts in the NHIS-D. DD data brief 2002;4 (1 NS-include).

159. Organisation $\mathrm{WH}$. International classification of functioning, disability and health-children and youth version. Geneva: World Health Organisation, 2007.

160. Marmot M, Friel S, Bell R, et al. Closing the gap in a generation: health equity through action on the social determinants of health. Lancet 2008;372:1661-9. 